\title{
BENCHMARKING ALCOHOL LITERACY: A MULTI-COUNTRY STUDY
}

Sharyn Rundle-Thiele, Griffith University, Australia Dariusz Siemieniako, Bialystok University of Technology, Poland Krzysztof Kubacki, Keele University, United Kingdom Sameer Deshpande, University of Lethbridge, Canada

\begin{abstract}
Prior studies suggest that people have poor health literacy and moreover individuals with limited health literacy have a significantly worse health status. Further, research suggests that high and appropriate levels of alcohol literacy are a prerequisite for moderate alcohol consumption, yet people are not adequately informed about alcohol. This paper seeks to benchmark alcohol literacy in three countries, namely Australia, Canada and Poland. Consideration of alcohol literacy requires that we use the same set of measures, some of which are contextualised, across countries. Following this approach convenience samples were used to collect data with over 400 in each sample.

The results of this study are consistent with prior alcohol knowledge studies who also noted knowledge gaps. Inspection of the knowledge questions indicate that a large proportion of adults were not able to correctly state the number of standard drinks in a glass of wine, or a bottle of full strength beer. Some adults were unable to correctly specify factors such as the number of standard drinks to safely drink and drive, daily drinking guidelines specified by national health bodies and the legal blood alcohol limit for adults. Implications for public policy are outlined.
\end{abstract}

References available upon request 